\section{Distrust and Poor Self-Reported Health Canaries in the Coal Mine?}

A growing body of research, including "Distrust of the Healthcare System and Self-Reported Health" published in the current issue of $\mathrm{JGIM}^{1}{ }^{1}$ seeks to understand the relevance of distrust to health outcomes, public health, and the provision of health care. The current study conceptualizes health care system distrust as creating access barriers to optimal health status. In this Editorial, we examine alternative perspectives to suggest that prevalent distrust reflects lack of trustworthiness exhibited by the health care system. We further assert that studying distrust is just one component of efforts to understand and address lack of trustworthiness in the health care system. Remedying the health care system's levels of trustworthiness is essential to ensure the provision of quality health care for all users.

Anderson et al. reported that, across race/ethnicity, distrust in the health care system (defined as hospitals, health insurance companies, and medical research) was prevalent and was inversely associated with self-reported health status. Interestingly, trust in physicians was not associated with health status. Although these findings underscore the relevance of trust to the practice of medicine, the presented interpretations reflect a common-and, we believe, problematicapproach: conceptualizing the patient as the source of the problem. This approach attributes poor health to patients' distrust without also considering ways that the system's (lack of) trustworthiness contributes to these effects.

An alternative interpretation of these findings (to which the authors briefly alluded) is that relative to healthier persons, those with the poorest health have more frequent and diverse interactions with the health care, which underlies their distrust of that system. Our sickest patients, because of more frequent or concentrated interactions, may become privy to and may themselves experience the frustrations that so many health care providers encounter when they strive to provide high-quality care to medically complex patients in a fragmented system. For those who are most medically vulnerable, hospitals and insurers may not appear to fulfill their fiduciary responsibility to patients. This insight may reveal the tenuousness of the health care system's ability to honor the social contract between the public and the profession, thus resulting in distrust that this system has the best interests of the public at heart. In this interpretation, distrust by our sickest and most medically vulnerable patients could be seen as a marker for a health care system ill equipped to provide for their needs. Patients with the poorest health therefore may be considered "canaries in the coal mine," their distrust being a warning sign of waning public trust.

In their conceptual model, the authors posit that patients' characteristics influence their health status through health care-related distrust and subsequent health behavior. However, by associating health status with both a measure of distrust of the health care system and patient characteristics, the mod-

Address correspondence and requests for reprints to Dr. Giselle Corbie-Smith: Department of Social Medicine, CB\# 7240 School of Medicine, University of North Carolina, Chapel Hill, NC 27599-7240 (e-mail: gcorbie@med.unc.edu). el may facilitate victim blaming and preclude broader opportunities for further research and intervention. Alternative conceptual models that build upon existing theoretical frameworks are possible. ${ }^{2-4}$ For example, Figure 1 illustrates 1 way in which the Andersen access to care model $^{5,6}$ could be used to explore these relationships. The model might include important characteristics of clinical interactions, reflecting the iterative nature of those interactions over time between patients, providers, and the health care system through which patients develop their perceptions. In addition, it could acknowledge that the relationship between patient characteristics, physician(s), and health care system characteristics is not unidirectional from patient to both providers and the system. Thus, a model that more fully represents the complexity of effects on patients' health status would have included provider and system characteristics.

This study's national sample is an important contribution to the literature on distrust; however, further research is necessary among those underrepresented and underserved within the health care system. Target groups for whom the implications of distrust may be particularly salient include racial/ ethnic minorities (less than $8 \%$ of this sample), uninsured persons (less than $14 \%$ of this sample), and persons who reside in society's social and economic margins, such as impoverished persons who bear a disproportionate burden of disease. As the authors suggest in their discussion, ecologic factors such as social capital within and across these groups may be relevant. To determine its effects, researchers must first describe how social cohesion, social capital, or other ecologic phenomena function within the specified socioecologic levels (e.g., neighborhoods) to affect health status.

Trust, distrust, and trustworthiness are related yet distinct concepts (Table 1) and each may have separate implications for interventions. ${ }^{7}$ In addition to measuring distrust in the system and trust in physicians, measuring trust in the health care system and distrust in physicians could help to illuminate each concept and possibly highlight ways that historical factors, cumulative or iterative exposures, and characteristics of the health care system contribute to distrust.

There are both conceptual and methodological ways that future research might complement this study and thus move the field forward. As with other research, this study aims to disaggregate the influences of important variables to understand their relationships to health outcomes. Such research provides an avenue by which to improve the quality of health care and the public's health. In recasting the findings, we shift the burden from patients and their levels of distrust to the health care system and its responsibility to demonstrate trustworthiness. We can then begin to examine our role as members of the health care system and identify the steps we can take to demonstrate our trustworthiness. Gruen et al. ${ }^{8}$ assert that "clear and visible leadership in the interests of the public's health is regarded ... as the best way for the medical profession to regain and retain the public trust that has diminished in recent decades." To the extent that health care providers represent the health care system, this study suggests our private interactions with and on behalf of individual patients may 


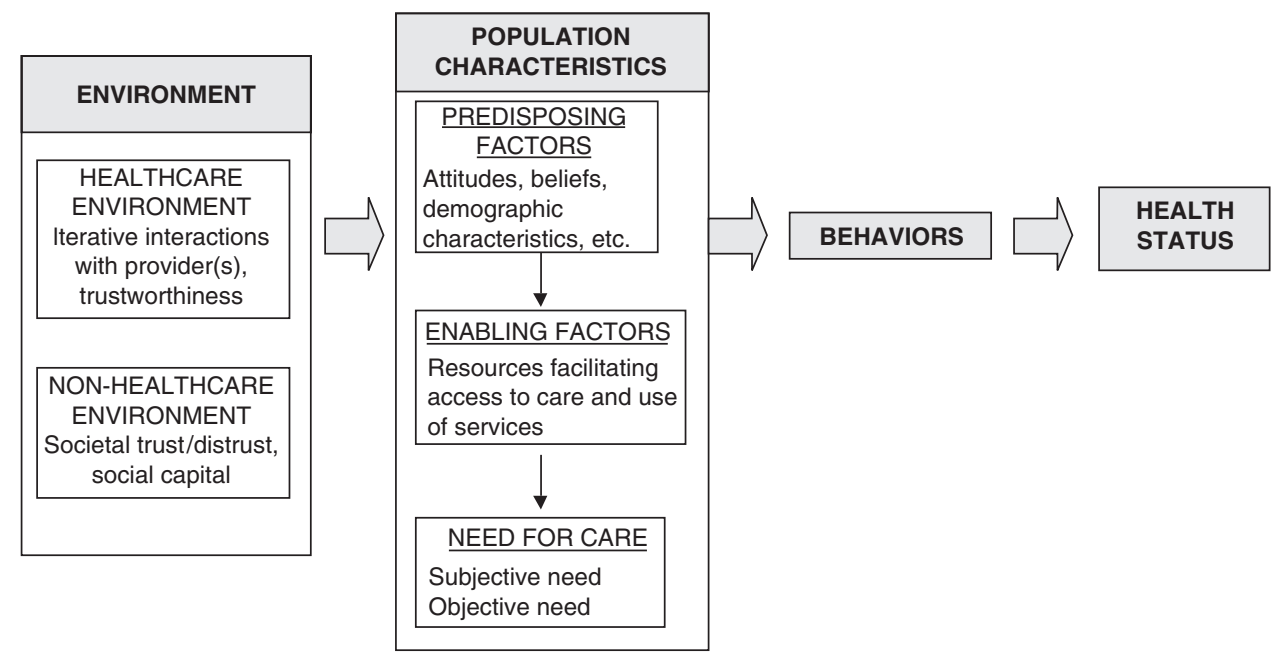

Fig. 1. Expanding an existing theoretical framework to study distrust, trustworthiness, and health status. Arrows show direction of influence and boxes indicate relevant factors adapted from Andersen. ${ }^{5}$

not be as important in shaping or influencing trust in the health care system as are our public roles as physician citizens. Implicit in the social contract between the public and the profession is the expectation that health care providers will do everything within their means to reduce the burden of illness and improve the public's health. Just as the canary warns coal miners of poor air quality, this study and others like it on distrust may highlight aspects of the health care system that lack trustworthiness.

As we think about our public role in demonstrating the trustworthiness of the health care system, several questions arise: How is patient-centered rather than physician-centered advocacy perceived by potential patients, and does this advocacy impact trust in a system of care? How can insurers, researchers, or hospitals demonstrate their fiduciary responsibility to the needs of those who have the poorest health status and thus the greatest health care needs? How can we demonstrate and improve the health care system's competence in caring for and coordinating the care of medically and socially complex patients through medical education and research? The challenge to researchers and practitioners is to understand how these public roles, interaction in these roles with the public, and our fulfillment of that social contract impact the ways that trust and trustworthiness are conceptualized by our patients, especially those most medically vulnerable.

We suggest the following avenues for research in this area. First, future studies should strive to understand the factors that create distrust by conducting group-specific examinations of these issues. Second, following multilevel conceptualizations of key relationships, future studies should use multilevel statistical analyses to simultaneously measure trustworthiness and distrust in ways that account for individual, interpersonal, and contextual effects.

The need for group-specific studies of trustworthiness and distrust builds upon research ${ }^{9-11}$ showing that the quality of care patients receive varies according to their personal characteristics. Factors influencing distrust, trust, and trustworthiness may be context-specific (e.g., according to type of institutions) and contingent upon the populations involved. Qualitative research within each group can help to clarify key components of distrust, trust, and trustworthiness and help researchers to determine the pathways by which each influences health care and, ultimately, health status for members of each group.

Multilevel statistical techniques are optimal for research that relies upon multilevel conceptual models ${ }^{12}$ to explain social determinants of health status. Whether future research assesses "trustworthiness" in lieu of or in addition to assessing "distrust," multilevel statistical techniques will help to provide richer understandings of these relationships. These methods can assess the extent to which both individuals' distrust and group level constructs such as institutions' characteristics, social capital, or societal trust influence health status. ${ }^{13}$

The title of this Editorial contains within it an implicit question: Why study distrust in the context of health care? We believe this research is important not only because it allows us to document prevalent distrust but also because it can guide us toward understanding a root cause of inadequate care, the health care system's lack of trustworthiness. The objectives of distrust research are 2-fold: (1) to understand how characteristics of the health care system can limit access to optimally provided care and (2) to use this knowledge to improve the delivery of care. Groups with limited access to care should be of high priority to this research because the effects of inaccessi-

Table 1. Standard Definitions of Trust, Distrust, and Trustworthiness

\begin{tabular}{|c|c|}
\hline Concept & Definition* \\
\hline Trust & $\begin{array}{l}\text { 1a. assured reliance on the character, ability, strength, } \\
\text { or truth of someone or something } \\
2 \text { a. to place confidence: depend; b. to be confident } \\
\text { Verb tense 1a: to commit or place in one's care or } \\
\text { keeping: entrust } \\
\text { Verb tense } 1 \text { b: to permit to stay or go or do something } \\
\text { without fear or misgiving } \\
\text { Verb tense } 2 \text { a: to rely on the truthfulness or accuracy of: } \\
\text { believe: to place confidence in }\end{array}$ \\
\hline Distrust & $\begin{array}{l}\text { 1. the lack or absence of trust } \\
2 \text {. to have no trust or confidence in }\end{array}$ \\
\hline Trustworthy & worthy of confidence: dependable \\
\hline
\end{tabular}

*Source: Merriam-Webster's Collegiate Dictionary. Springfield, MA: Merriam-Webster, Inc.; 1991. 
bility are considerable for them. As providers, we have an important responsibility to use this knowledge to enhance the trustworthiness of the health care system. - Giselle CorbieSmith, MD, MSc ${ }^{1,2}$ and Chandra L. Ford, PhD, MPH, MLIS, ${ }^{1}$ ${ }^{1}$ Department of Social Medicine, University of North Carolina, Chapel Hill, NC, USA; ${ }^{2}$ Department of Medicine, University of North Carolina, Chapel Hill, NC, USA

\section{REFERENCES}

1. Anderson K, Rose A, Peters N, Long JA, McMurphy S, Shea JA. Distrust of the health care system and reported health in the US. J Gen Intern Med. 2006;21.

2. Phillips KA, Morrison KR, Andersen R, Aday LA. Understanding the context of healthcare utilization: assessing environmental and providerrelated variables in the behavioral model of utilization. Health Serv Res. 1998;33:571-95.

3. Earp JA, Ennett ST. Conceptual models for health education research and practice. Health Educ Res. 1991;6:163-71.

4. Glanz K, Rimer BK. Theory at a Glance: A Guide for Health Promotion Practice. Bethesda, MD: US Department of Health and Human Services, Public Health Service, NIH, NCI; 1997.
5. Andersen RM. Revisiting the behavioral model and access to medical care: does it matter. J Health Soc Behav. 1995;36:1-10.

6. Andersen RM, Newman JF. Societal and individual determinants of medical care utilization in the United States. Milbank Mem Fund $Q$ Health Soc. 1973;51:95-124.

7. Crawley LM. African-American participation in clinical trials: situating trust and trustworthiness. J Natl Med Assoc. 2001;93(12 Suppl):14S-7S.

8. Gruen RL, Pearson SD, Brennan TA. Physician-citizens-public roles and professional obligations. JAMA. 2004;29:94-8.

9. van Ryn M, Burke J. The effect of patient race and socio-economic status on physicians' perceptions of patients. Soc Sci Med. 2000;50: 813-28.

10. van Ryn M, Fu SS. Paved with good intentions: do public health and human service providers contribute to racial/ethnic disparities in health. Am J Public Health. 2003;93:248-55.

11. Schulman KA, Berlin JA, Harless W, et al. The effect of race and sex on physicians' recommendations for cardiac catheterization. N Engl J Med. 1999;340:618-26.

12. McLeroy KR, Bibeau D, Steckler A, Glanz K. An ecological perspective on health promotion programs. Health Educ Q. 1988;15: 351-77.

13. Duncan C, Jones K, Moon B. Health-related behaviour in context: a multilevel modeling approach. Soc Sci Med. 1996;42:817-30. 